\title{
MANEJO DO NITROGÊNIO NO MILHO EM SEMEADURA DIRETA EM SUCESSÃO A ESPÉCIES DE COBERTURA DE SOLO NO INVERNO E EM DOIS LOCAIS. I - EFEITO SOBRE A ABSORÇÃO DE N ${ }^{1}$
}

\author{
NITROGEN MANAGEMENT IN MAIZE IN NO-TILL SYSTEM IN SUCCESSION TO \\ WINTER COVER CROPS IN TWO LOCATIONS. I - EFFECT ON N UPTAKE
}

\author{
Gilber Argenta ${ }^{2}$ Paulo Regis Ferreira da Silva ${ }^{3}$ Mauro Antônio Rizzardi ${ }^{4}$ \\ Marcos João Baruffi ${ }^{5}$ Vasco Beheregaray Neto ${ }^{6}$
}

\section{RESUMO}

A permanência de restos culturais sobre a superficie do solo altera os processos de imobilização e mineralização, diminuindo a disponibilidade de nitrogênio para o milho, principalmente, em sucessão a gramíneas. O objetivo do trabalho foi o de avaliar, em dois ambientes, os efeitos de dose e época de aplicação de $\mathrm{N}$ no milho (0-0; 0-160; 30-130 e 60-100kg/ha, respectivamente, na semeadura e em cobertura), em sistema de semeadura direta, implantado em duas épocas após a dessecação (1 e aos 20 dias) de duas coberturas de solo no inverno (aveia preta e ervilhaca comum) e da área em pousio invernal livre de plantas daninhas, sobre a absorção de N. Foram conduzidos dois experimentos com suplementação hídrica, sendo um em Eldorado do Sul e outro em Passo Fundo, no estado do Rio Grande do Sul, no ano agrícola 1996/97. Em Eldorado do Sul, a aplicação de $N$ na semeadura foi benéfica, pois aumentou a absorção de $\mathrm{N}$ em relação ao tratamento com todo o $N$ em cobertura, independentemente da cobertura de solo no inverno testada. Em Passo Fundo, somente no estádio de 3-4 folhas, houve vantagem da aplicação de $N$ na semeadura em relação à aplicação total em cobertura sobre a absorção de N. Nos estádios de 6-7 folhas, 1011 folhas e de pendoamento do milho, não houve diferença entre os tratamentos com N. O atraso na época de semeadura do milho, após a dessecação em 20 dias, mostra-se tecnicamente viável, principalmente quando em sucessão à aveia preta, pois aumentou na média dos sistemas de manejo de $N 54$ e $75 \%$ a absorção de $N$, no estádio de 3-4 folhas, respectivamente em Eldorado do Sul e em Passo Fundo. A absorção de $N$ no tecido da planta de milho em sucessão à aveia preta foi menor em Eldorado do Sul do que em Passo Fundo, em todos os estádios avaliados. $O$ aumento na dose de $N$, na semeadura, de 30 para $60 \mathrm{~kg} / \mathrm{ha}$ de $N$, não se constituiu em estratégia eficiente para aumentar a absorção de $N$, independentemente da cobertura de solo no inverno.

Palavras-chave: espécies de cobertura de solo no inverno, Zea mays L., época de semeadura após a dessecação, dose e época de aplicação de $N$.

\section{SUMMARY}

The permanence of cultural residues on soil surface modifies the processes of immobilization and mineralization, reducing $N$ availability to maize, especially in succession to grasses. The objective this study was to evaluate, in two locations, the effects of rate and timimg of $N$ application in maize $(0-0 ; 0$ $160 ; 30-130$ and $60-100 \mathrm{~kg} / \mathrm{ha}$, respectively, at sowing and sidedressed), in no-till system, established in two sowing dates after desiccation ( 1 and 20 days) of two winter cover crops (black oat and common vetch) and bare area without weeds, on $N$ uptake. The research was conducted at two locations of the state of Rio Grande do Sul, Brazil, in the 1996/97 growing season. In Eldorado do Sul, $N$ application at sowing was beneficial because it increased $N$ uptake in relation to the treatment with total $N$ sidedressed, regradless of the species of winter crop tested. At Passo Fundo, only in the stage of 3-4 leaves there was advantage of $N$ application at sowing in relation to total sidedressed application. In the stages of 6-7 leaves, 10-11 leaves and of tasseling there were no differences among the treatments with $N$ application. The delay of maize sowing date after desiccation in 20 days is a management practice that could be used, specially when maize follows black oat, since it increased, at the average at the $N$ management systems, 54 e $75 \% N$ uptake, respectively in

${ }^{1}$ Artigo extraído da Dissertação de Mestrado do primeiro autor.

${ }^{2}$ Engenheiro Agronômo, MSc., Doutorando no Curso de Pós-graduação em Fitotecnia, Faculdade de Agronomia, Universidade Federal do Rio Grande do Sul (UFRGS). Bolsista do CNPq, Av. Bento Gonçalves, 7712, CP 776, 91540-000, Porto Alegre,RS. E-mail: argentag@vortex.ufrgs.br. Autor para correspondência.

${ }^{3}$ Engenheiro Agronômo, PhD., Professor Adjunto, Departamento de Plantas de Lavoura, Faculdade de Agronomia, UFRGS. Bolsista do CNPq.

${ }^{4}$ Engenheiro Agronômo, MSc., Professor do Departamento de Fitotecnia, Faculdade de Agronomia, UPF.

${ }^{5}$ Acadêmico da Faculdade de Agronomia, UPF.

${ }^{6}$ Acadêmico da Faculdade de Agronomia, UFRGS. Bolsista de iniciação científica do CNPq. 
Eldorado do Sul and in Passo Fundo. $N$ uptake by maize in succession to black oat was lower at Eldorado do Sul that in Passo Fundo, in all stages of development tested. The increment of $N$ rate from 30 to $60 \mathrm{~kg} / \mathrm{ha}$ did not increase $N$ uptake by maize plants, regardless of cover crop in the winter.

Key words: winter cover crops, Zea mays L., sowing date after desiccation, rate and timing of $N$ application.

\section{INTRODUÇÃO}

A manutenção de resíduos culturais na superfície do solo no sistema de semeadura direta promove condições distintas às propriedades do solo, em relação à sua incorporação através do preparo convencional. O não revolvimento do solo determina a decomposição mais lenta e gradual do material orgânico (AULAKH $\boldsymbol{e t} \boldsymbol{a l}$., 1991), tendo como conseqüência alterações físicas, químicas e biológicas, que irão repercutir na fertilidade do solo e na produtividade das culturas (MOODY et al., 1961).

Um dos fatores mais importantes que governa a taxa de decomposição de resíduos culturais é a sua composição química (JANSEM \& KUCEY, 1988). Grandes diferenças na taxa de decomposição e de liberação de nutrientes foram observadas em função dos tipos de resíduos, particularmente nos estágios iniciais de decomposição (SCHOMBERG et al., 1994). Isso é atribuído às variações nas características dos resíduos das culturas, incluindo os teores de nitrogênio $(\mathrm{N})$, de lignina, de vários carboidratos e de substâncias solúveis em água (REINERTSEN $\boldsymbol{e} t$ $\boldsymbol{a l} ., 1984)$, e as variações de ambiente (STOTT $\boldsymbol{e t} \boldsymbol{a l}$., 1986).

A relação $\mathrm{C} / \mathrm{N}$ de resíduos de coberturas de solo indica se há predominância da mineralização líquida, ou da imobilização líquida de $\mathrm{N}$, durante a fase inicial de sua decomposição e a quantidade de $\mathrm{N}$ liberada para o solo. A relação $\mathrm{C} / \mathrm{N}$ entre 23 e 24 favorece a mineralização de resíduos vegetais (DERPSCH $\boldsymbol{e}$ t al., 1991; HEINZMANN, 1985). Quando a relação C/N se encontra em torno de 20, começa a ocorrer a mineralização do $\mathrm{N}$ através da decomposição da biomassa microbiana, a qual se estabiliza com valor em torno de 10 a 12 (DOUGLAS et al., 1980). Portanto, quando a necessidade de $\mathrm{N}$ dos microorganismos não é suprida, pode haver deficiência temporária deste elemento para a cultura, em condições de campo, devida à sua imobilização (KIEHL, 1985).

A mineralização de $\mathrm{N}$ de resíduos culturais é influenciada pelo regime nutricional de $\mathrm{N}$, sendo tanto maior quanto maior é o teor de $\mathrm{N}$ nos tecidos (JANSEN \& KUCEY, 1988), e maior a quantidade de resíduos da cobertura de solo (TOLLENAAR $\boldsymbol{e t}$ al., 1993).

Outro fator que afeta a disponibilidade de $\mathrm{N}$ no solo é a seqüência de espécies de culturas em sucessão. Combinações de culturas com maior predominância de gramíneas mantêm a cobertura no solo por períodos mais longos. No entanto, há necessidade de maior atenção para a adubação nitrogenada na semeadura, para compensar o efeito de imobilização de $\mathrm{N}$ pelos microorganismos na fase inicial de crescimento das culturas em sucessão a gramíneas.

O milho cultivado em sucessão a gramíneas pode apresentar menor produção de massa seca e menor absorção de $\mathrm{N}$ em relação ao semeado em sucessão a leguminosas, conforme verificaram DA ROS \& AITA (1996), TEIXEIRA $\boldsymbol{e t}$ al. (1994), AITA et al. (1994) e TIAN et al. (1993). Estas reduções são atribuídas ao fato de que a adição de quantidades elevadas de resíduos culturais, com alta relação $\mathrm{C} / \mathrm{N}$, faz com que os microorganismos quimiorganotróficos, que atuam na decomposição da matéria orgânica, multipliquem-se gradativamente, produzindo $\mathrm{CO}_{2}$ em grande quantidade. Como conseqüência, o nitrato e o amônio presentes no solo, praticamente, desaparecem (VICTORIA et al., 1992).

Para diminuir a deficiência inicial de $\mathrm{N}$ na cultura do milho, em sucessão a gramíneas, recomenda-se para qualquer situação a sua aplicação em doses mais elevadas na semeadura (SÁ, 1993, COMISSÃO...1995). A absorção de $\mathrm{N}$ ocorre durante todo o seu ciclo vegetativo, sendo pequena na fase inicial (FORNASIERI FILHO, 1992). O milho necessita de grande quantidade de $\mathrm{N}$, estimando-se que metade da quantidade absorvida pela planta provenha do solo (CANTARELLA, 1993). Portanto, a absorção de N poderá ser alterada em função do ambiente, determinando a necessidade de sua avaliação em locais com características distintas.

O objetivo do presente trabalho foi de avaliar, em dois locais, os efeitos de dose e época de aplicação de $\mathrm{N}$ em milho, em sistema de semeadura direta, implantado em duas épocas após a dessecação de aveia preta e de ervilhaca comum e em área em pousio invernal sobre a absorção de N.

\section{MATERIAL E MÉTODOS}

O trabalho foi conduzido a campo em dois locais, com suplementação hídrica. O primeiro experimento foi instalado na Estação Experimental Agronômica (EEA) da Universidade Federal do Rio 
Grande do Sul, localizada no município de Eldorado do Sul, região fisiográfica da Depressão Central do estado do Rio Grande do Sul, à altitude média de 46 $\mathrm{m}$. O solo da área experimental pertence à unidade de mapeamento São Jerônimo, classificado como podzólico vermelho escuro (Paleudult) (IBGE, 1986). O clima da região é classificado, segundo Köppen, como subtropical úmido, situado na transição entre os tipos fundamentais cfa (isoterma $_{1}$ anual inferior a $18^{\circ} \mathrm{C}$ ) e $\mathrm{cfa}_{2}$ (isoterma anual superior a $18^{\circ} \mathrm{C}$ ) (MORENO, 1961). As temperaturas médias anual, máxima e mínima são de, respectivamente, 19,6, 24,3 e $14,8^{\circ} \mathrm{C}$ (IPAGRO, 1979).

O segundo experimento foi conduzido no Centro de Extensão e Pesquisa Agronômica (CEPAGRO) da Faculdade de Agronomia e Medicina Veterinária da Universidade de Passo Fundo (FAUPF), localizado na região fisiográfica do Planalto Médio do estado do Rio Grande do Sul, à altitude média de 709m. O solo da área experimental pertence à unidade de mapeamento Passo Fundo, classificado como latossolo vermelho escuro distrófico (BRASIL, 1973). O clima da região é classificado, segundo Köppen, como subtropical (cfa) (MORENO, 1961). As temperaturas médias anual, máxima e mínima são de respectivamente, 18,4, 23,8 e 12,7 (IPAGRO, 1979).

Nos dois locais, os tratamentos constaram da utilização de duas espécies de cobertura de solo no inverno, [aveia preta (Avena strigosa Scheib) e ervilhaca comum (Vicia sativa L.) e da área em pousio invernal, duas épocas de implantação de milho após a dessecação (1 e 20 dias)] e de quatro sistemas de manejo de $\mathrm{N}$ (sem $\mathrm{N}$ na semeadura e em cobertura; sem $\mathrm{N}$ na semeadura e com $160 \mathrm{~kg} / \mathrm{ha}$ de $\mathrm{N}$ em cobertura; $30 \mathrm{~kg} / \mathrm{ha}$ de $\mathrm{N}$ na semeadura e $130 \mathrm{~kg} / \mathrm{ha}$ de $\mathrm{N}$ em cobertura e $60 \mathrm{~kg} / \mathrm{ha}$ de $\mathrm{N}$ na semeadura e $100 \mathrm{~kg} / \mathrm{ha}$ de $\mathrm{N}$ em cobertura). O delineamento experimental utilizado foi o de blocos casualizados, com quatro repetições, dispostos em parcelas subsubdivididas. As coberturas de inverno foram locadas na parcela principal, as épocas de implantação de milho nas subparcelas e os sistemas de manejo de $\mathrm{N}$ nas subsubparcelas.

A análise de solo, realizada antes da implantação dos experimentos, indicou, respectivamente para Eldorado do Sul e para Passo Fundo, 38 e $59 \%$ de argila, 2,2 e 3,4\% de matéria orgânica, 9 e $5 \mathrm{mg} \mathrm{L}^{-1}$ de fósforo, 168 e $95 \mathrm{mg} \mathrm{L}^{-1}$ de potássio e $\mathrm{pH}\left(\mathrm{H}_{2} \mathrm{O}\right)$ de 5,2 e 6,0 , de acordo com metodologia descrita em TEDESCO et al. (1985).

A aveia e a ervilhaca foram implantadas em sistema de semeadura direta, no espaçamento entre linhas de $0,16 \mathrm{~m}$. As duas espécies não foram adubadas na sua implantação. $\mathrm{Na}$ aveia, foram aplicados em cobertura $60 \mathrm{~kg} / \mathrm{ha}$ de $\mathrm{N}$ em duas doses iguais, sendo a primeira no estádio de 3-4 perfilhos e a segunda no de 6-7 perfilhos.

Procedeu-se a dessecação das duas espécies quando $50 \%$ das plantas da aveia preta estavam em plena floração, utilizando-se o herbicida glyphosate (540g e.a./ha), no volume de 100 litros de calda/ha. As áreas correspondentes ao pousio invernal foram mantidas livres de plantas daninhas através de aplicações de herbicidas. Em Passo Fundo, neste tratamento, ocorreu reinfestação com espécies gramíneas, principalmente.

$\mathrm{O}$ genótipo de milho utilizado foi $\mathrm{o}$ Pioneer 3063, híbrido triplo, de ciclo precoce, utilizando-se a densidade de 70.000 plantas/ha e o espaçamento entre linhas de $0,7 \mathrm{~m}$. Cada subsubparcela foi composta por 8 linhas de 6 metros de comprimento. As quatro primeiras linhas foram utilizadas para avaliação do rendimento de grãos e seus componentes. As demais linhas foram utilizadas para as determinações de produção de massa seca e absorção de $\mathrm{N}$ por planta. A adubação foi realizada na linha, por ocasião da semeadura, utilizando-se $150 \mathrm{~kg} / \mathrm{ha}$ de $\mathrm{P}_{2} \mathrm{O}_{5}$ e $100 \mathrm{~kg} / \mathrm{ha}$ de $\mathrm{K}_{2} \mathrm{O}$. A aplicação de $\mathrm{N}$ em cobertura foi parcelada em duas doses iguais, sendo a primeira no estádio de 3-4 folhas completamente desenvolvidas, e a segunda no de 6-7 folhas completamente desenvolvidas. A semeadura foi realizada manualmente (saraquá), colocando-se três a quatro sementes por cova. Aos 20 dias após a emergência, foi realizado desbaste, deixando-se uma planta por cova.

Para determinar-se a absorção de N, foram coletadas cinco plantas de milho por subsubparcela nos estádios de 3-4, 6-7 e de 10-11 folhas completamente desenvolvidas e de início do pendoamento. Nas coletas de plantas nos estádios de 10-11 folhas completamente desenvolvidas e de início do pendoamento, as plantas dos tratamentos sem N encontravam-se, respectivamente, nos estádios de 7-8 e de 11-12 folhas completamente desenvolvidas.

A produção de massa seca por planta de milho foi obtida através da coleta da parte aérea de cinco plantas por subsubparcela, postas a secar em estufa a $60^{\circ} \mathrm{C}$ até atingirem peso constante. $\mathrm{O}$ teor de $\mathrm{N}$ no tecido foi determinado de acordo com metodologia descrita em TEDESCO et al. (1985). A quantidade de $\mathrm{N}$ absorvida na parte aérea da planta foi obtida multiplicando-se a produção de massa seca por planta pelo teor de $\mathrm{N}$ presente na fitomassa.

Os dados de absorção de $\mathrm{N}$ foram submetidos à análise de variância complexa. A comparação entre médias foi realizada através do teste de Duncan, em nível de 5\% de probabilidade. $\mathrm{Na}$ análise conjunta dos locais, considerou-se o local 
como fator aleatório. A estimativa dos componentes de variância foi obtida de acordo com regra de Hicks (RIBOLDI, 1993).

\section{RESULTADOS E DISCUSSÃO}

Os dados de absorção de $\mathrm{N}$ pelas plantas de milho em sucessão à aveia preta, à ervilhaca comum e ao pousio invernal encontram-se, respectivamente, nas tabelas 1,2 e 3 .

As plantas do tratamento sem aplicação de $\mathrm{N}$ absorveram quantidades de $\mathrm{N}$ similares às do tratamento com todo $\mathrm{N}$ aplicado em cobertura, no estádio de 3-4 folhas, independentemente do local, da espécie de cobertura de solo no inverno e do pousio invernal e da época de semeadura após a dessecação (tabelas 1, 2 e 3). Nos estádios de 6-7 folhas, 10-11 folhas e de pendoamento, o tratamento com aplicação total de $\mathrm{N}$ em cobertura proporcionou maior absorção de $\mathrm{N}$ em relação ao sem aplicação de $\mathrm{N}$, com exceção do estádio de 6-7 folhas em sucessão à ervilhaca em Passo Fundo, em que não houve diferença entre tratamentos.

Em geral, o incremento na dose de $\mathrm{N}$ na semeadura de 30 para $60 \mathrm{~kg} / \mathrm{ha}$ não aumentou a absorção de $\mathrm{N}$ pelo milho nos dois locais e nas duas espécies de cobertura de solo no inverno e no pousio invernal (tabelas 1, 2 e 3).

Em Eldorado do Sul, em todos os estádios avaliados, as plantas dos tratamentos com aplicação de $\mathrm{N}$ na semeadura do milho em sucessão à aveia preta absorveram mais $\mathrm{N}$ do que as sem aplicação de $\mathrm{N}$ na semeadura, nas duas épocas de semeadura, apesar de, estatisticamente, nos estádios de 10-11 folhas e de pendoamento, os tratamentos com aplicação total de $\mathrm{N}$ em cobertura não diferirem do com aplicação de $60 \mathrm{~kg} / \mathrm{ha}$ de $\mathrm{N}$ na semeadura e de $100 \mathrm{~kg} / \mathrm{ha}$ de $\mathrm{N}$ em cobertura (tabela 1). Em Passo Fundo, na semeadura 1 dia após a dessecação, nos estádios de 3-4 folhas e de 6-7 folhas, as plantas do tratamento com aplicação de $\mathrm{N}$ na semeadura absorveram mais $\mathrm{N}$ do que as com aplicação total em cobertura (tabela 1). Na semeadura 20 dias após a dessecação, no estádio de 3-4 folhas, não houve diferença na absorção de $\mathrm{N}$ entre as plantas dos tratamentos com N. No estádio de 6-7 folhas, o tratamento com aplicação total de $\mathrm{N}$ em cobertura proporcionou maior absorção de $\mathrm{N}$ do que os com aplicação de N na semeadura. Nos estádios de 10-11 folhas e de pendoamento, não se verificou diferença na absorção de $\mathrm{N}$ entre as plantas dos tratamentos com $\mathrm{N}$, independentemente da época de semeadura.

A resposta diferencial na absorção de $\mathrm{N}$ entre os ambientes pode ser atribuída ao maior teor de matéria orgânica do solo de Passo Fundo $(3,4 \%)$ em relação ao de Eldorado do Sul (2,2\%), em que as necessidades iniciais de $\mathrm{N}$ pelo milho foram supridas, provavelmente, através do processo de mineralização basal. Outro fator que pode ter determinado a falta de resposta à aplicação de $\mathrm{N}$ na semeadura em Passo Fundo, relaciona-se ao sistema de culturas utilizado anteriormente. Nos últimos dois anos agrícolas, foi cultivada soja no verão, que deve ter contribuído para aumentar os teores de N no solo (MUZILLI \& OLIVEIRA, 1992). Já em Eldorado do Sul, foi estabelecida a sucessão aveia e milho desde o início da implantação do sistema de semeadura direta. Esta seqüência de culturas, por ser composta apenas por gramíneas e, portanto, implicar adição de resíduos de alta relação $\mathrm{C} / \mathrm{N}$, contribuiu para diminuir, ou manter baixos, os teores de $\mathrm{N}$ no solo neste local.

$\mathrm{O}$ atraso na época de semeadura do milho em 20 dias após a dessecação da aveia, no estádio de 3-4 folhas, aumentou, na média dos sistemas de manejo de N, 54 e 75\%, a absorção de N pelas plantas, respectivamente em Eldorado do Sul e em Passo Fundo (tabela 1). Em Eldorado do Sul, no estádio de 6-7 folhas, não houve efeito da época de semeadura. Já em Passo Fundo, nos tratamentos sem aplicação de $\mathrm{N}$, verificou-se maior absorção de $\mathrm{N}$ na segunda época em relação à primeira época de semeadura. Nos tratamentos com aplicação de N, as plantas absorveram mais $\mathrm{N}$ na primeira época em relação à segunda época de semeadura. Nos estádios de 10-11 folhas e de pendoamento, não houve efeito de época de semeadura na absorção de $\mathrm{N}$ pelo milho, nos dois locais.

A maior absorção de $\mathrm{N}$ pelas plantas de milho observada na segunda época em relação à primeira, nos dois locais, no estádio de 3-4 folhas, pode estar associada ao processo de decomposição de resíduos de aveia. $O$ atraso na época de semeadura diminui a relação $\mathrm{C} / \mathrm{N}$, uma vez que o carbono está sendo perdido na forma de $\mathrm{CO}_{2}$ e o nitrogênio conservado pela formação da massa celular microbiana (VICTORIA et al., 1992) e favorece a implantação de milho em épocas de semeadura com menor competição por $\mathrm{N}$ com os microorganismos.

Em todos os sistemas de manejo de $\mathrm{N}$, a quantidade de $\mathrm{N}$ absorvida pelas plantas de milho em sucessão à aveia foi superior em Passo Fundo em relação a Eldorado do Sul, nas duas épocas de semeadura após a dessecação, com exceção dos tratamentos com aplicação de $\mathrm{N}$ na semeadura na segunda época, no estádio de 6-7 folhas, em que a quantidade de $\mathrm{N}$ absorvida pelas plantas foi similar entre locais (tabela 1). Esta resposta diferencial entre locais pode ser atribuída ao maior rendimento de 
Tabela 1 - Análise conjunta da quantidade de nitrogênio $(\mathrm{N})$ total absorvida pelo milho (mg/planta) em quatro estádios de desenvolvimento, em duas épocas de semeadura após a dessecação da aveia preta, em dois locais do Rio Grande do Sul, sob quatro sistemas de manejo de N. 1996/97.

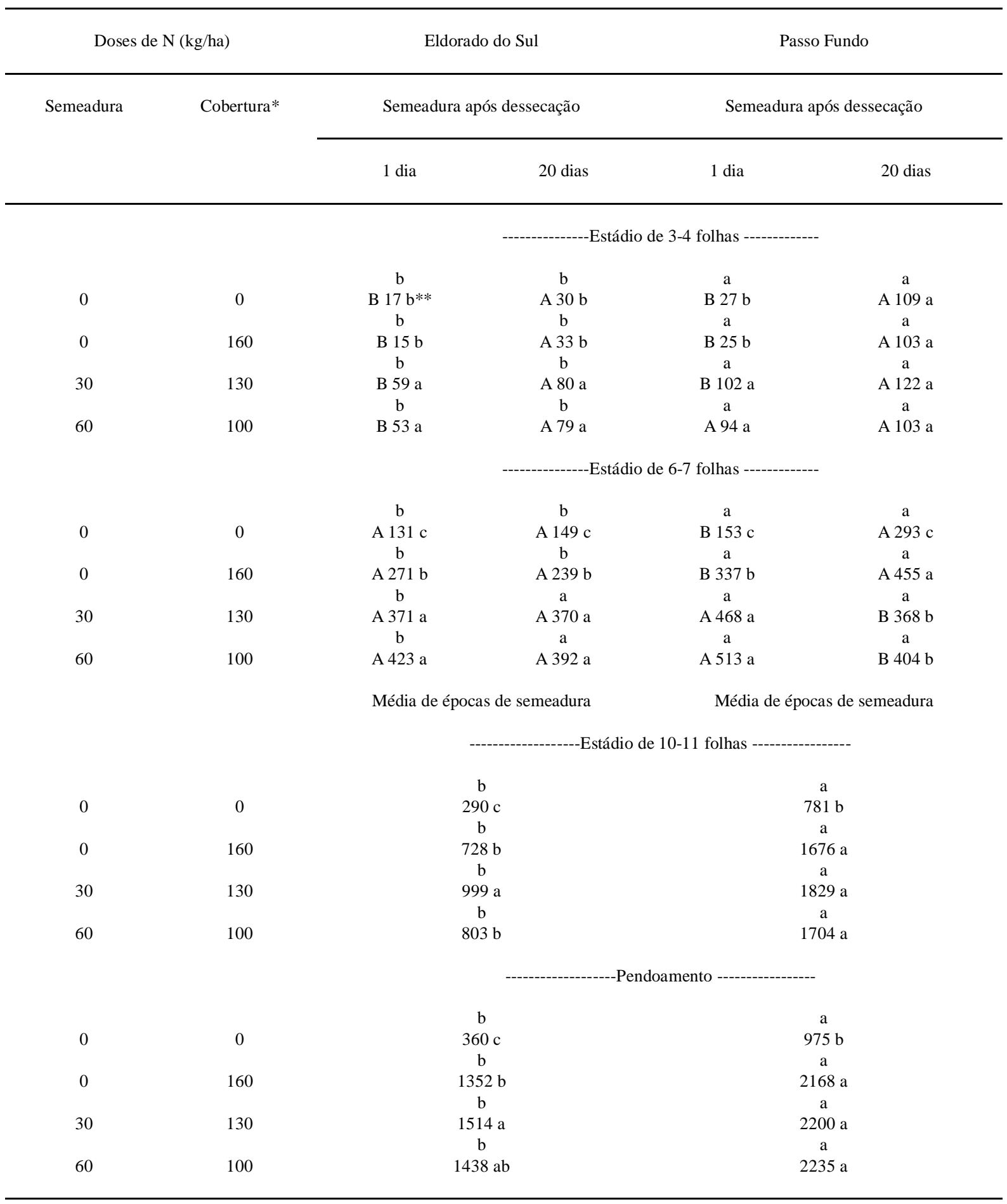

*Aplicado em duas doses iguais, nos estádios de 3-4 folhas e de 6-7 folhas completamente desenvolvidas de milho.

**Médias que são antecedidas pela mesma letra maiúscula na linha comparam épocas de semeadura dentro de locais; seguidas por letra minúscula na coluna comparam sistemas de manejo de $\mathrm{N}$ dentro de época de semeadura; letras minúsculas em superescrito comparam locais no mesmo nível de época de semeadura e de sistemas de manejo de N, não diferem significativamente entre si pelo teste de Duncan, em nível de $5 \%$ de probabilidade.

Ciência Rural, v. 29, n. 4, 1999. 
Tabela 2 - Análise conjunta da quantidade de nitrogênio (N) total absorvida pelo milho (mg/planta) em quatro estádios de desenvolvimento, em duas épocas de semeadura após a dessecação da ervilhaca comum, em dois locais do Rio Grande do Sul, sob quatro sistemas de manejo de N. 1996/97.

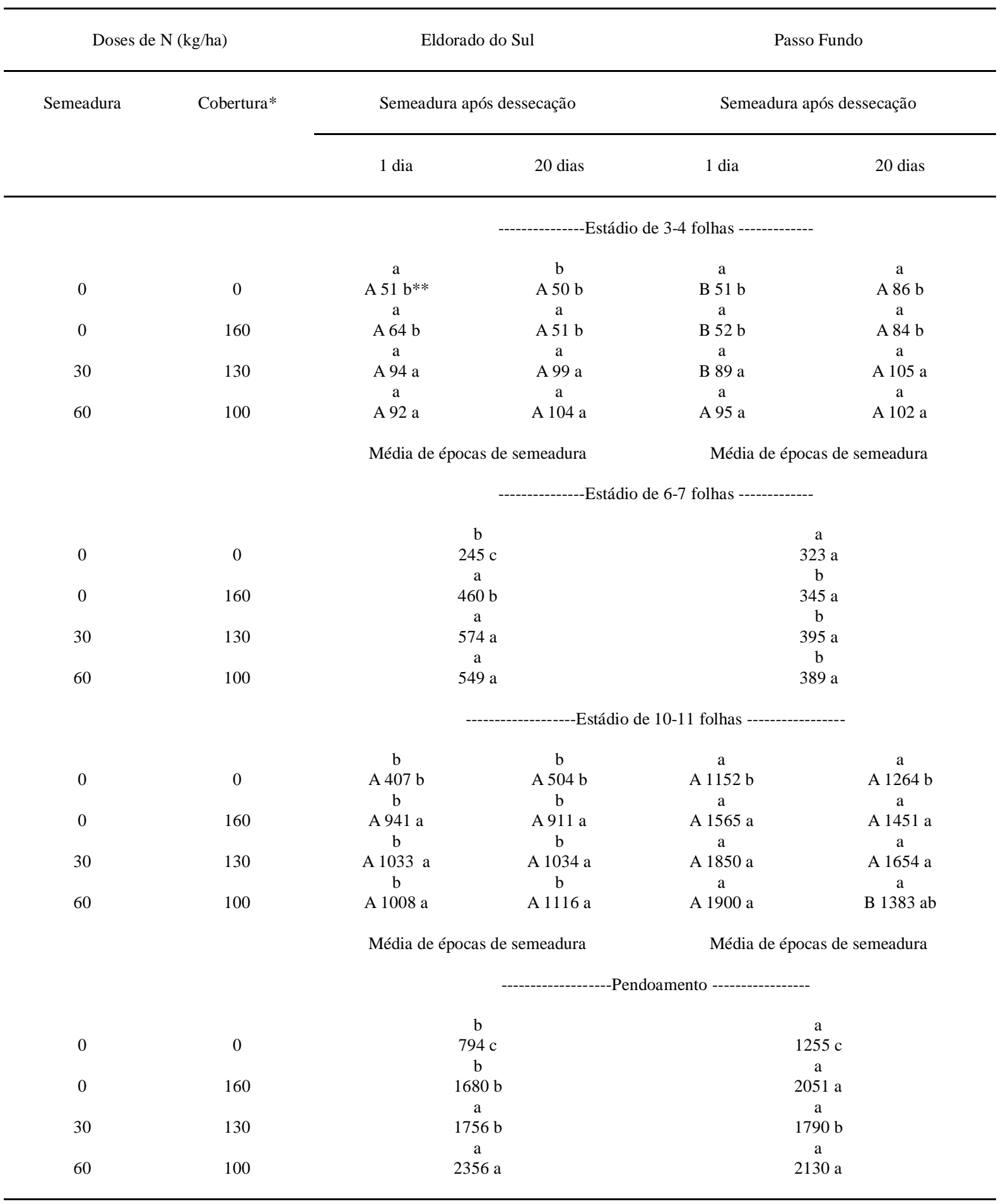

*Aplicado em duas doses iguais, nos estádios de 3-4 folhas e de 6-7 folhas completamente desenvolvidas de milho.

**Médias que são antecedidas pela mesma letra maiúscula na linha comparam épocas de semeadura dentro de locais; seguidas por letra minúscula na coluna comparam sistemas de manejo de $\mathrm{N}$ dentro de época de semeadura; letras minúsculas em superescrito comparam locais no mesmo nível de época de semeadura e de sistemas de manejo de N, não diferem significativamente entre si pelo teste de Duncan, em nível de $5 \%$ de nrohahilidade.

Ciência Rural, v. 29, n. 4, 1999. 
Tabela 3 - Análise conjunta da quantidade de nitrogênio (N) total absorvida pelo milho (mg/planta) em quatro estádios de desenvolvimento, em duas épocas de semeadura após a dessecação do tratamento pousio invernal, em dois locais do Rio Grande do Sul, sob quatro sistemas de manejo de N. 1996/97.

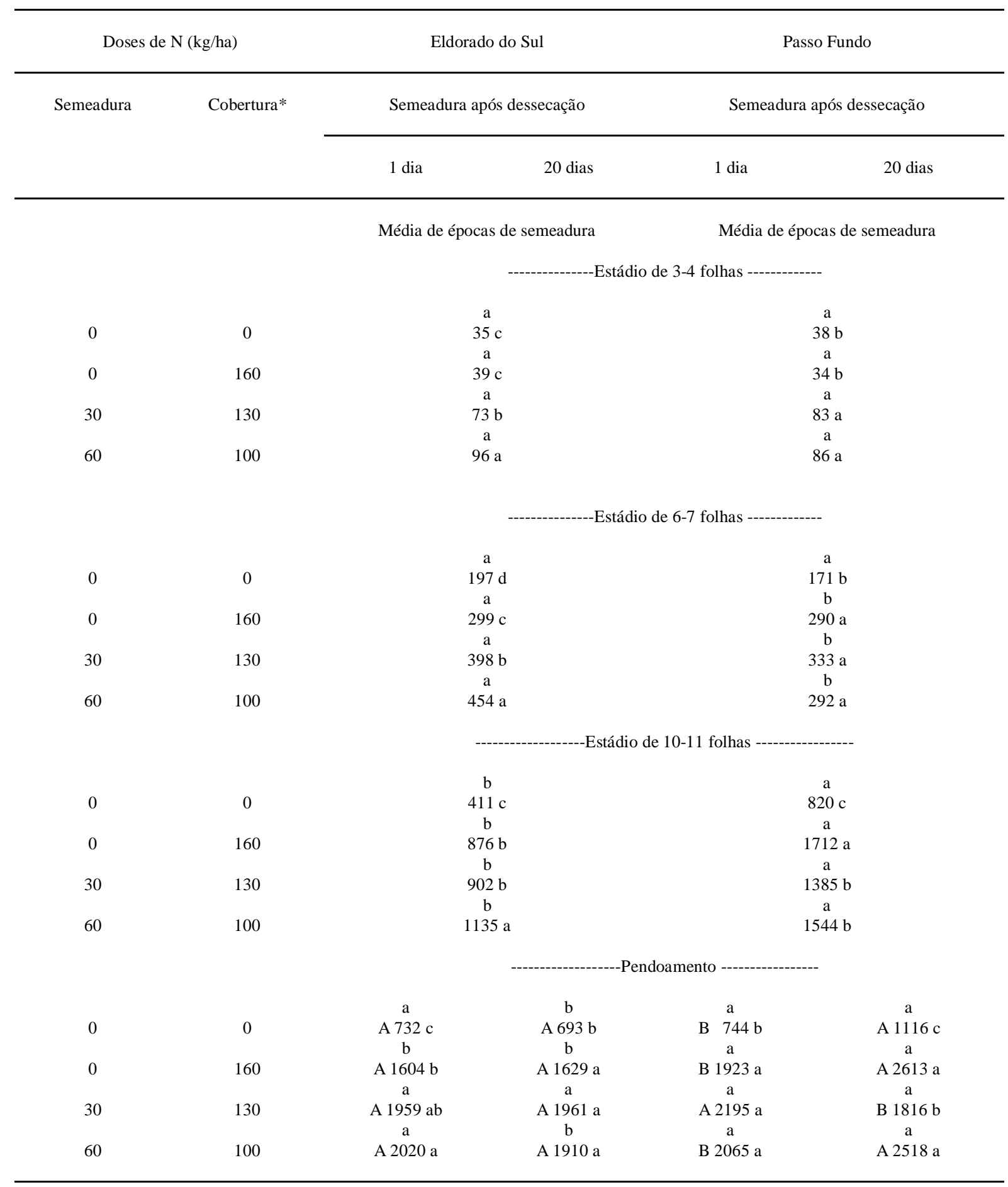

*Aplicado em duas doses iguais, nos estádios de 3-4 folhas e de 6-7 folhas completamente desenvolvidas de milho.

**Médias que são antecedidas pela mesma letra maiúscula na linha comparam épocas de semeadura dentro de locais; seguidas por letra minúscula na coluna comparam sistemas de manejo de $\mathrm{N}$ dentro de época de semeadura; letras minúsculas em superescrito comparam locais no mesmo nível de época de semeadura e de sistemas de manejo de N, não diferem significativamente entre si pelo teste de Duncan, em nível de $5 \%$ de probabilidade.

Ciência Rural, v. 29, n. 4, 1999. 
massa seca de aveia em Eldorado do Sul (6,5t/ha) em relação a Passo Fundo (5,8t/ha) e ao menor teor de nitrogênio do solo em relação aos obtidos em Passo Fundo. Em conseqüência, em Eldorado do Sul houve menor decomposição de restos culturais de aveia em relação a Passo Fundo, respectivamente 23 e $43 \%$. Isso determina um efeito inibidor da palha da aveia sobre a planta de milho mais prolongado, pois em solos com baixos teores de $\mathrm{N}$ mineral pode haver limitações no crescimento microbiano e, portanto, na decomposição da palha (AITA, 1997).

Em sucessão à ervilhaca, nos estádios de 3-4 folhas e de 6-7 folhas de milho, as plantas dos tratamentos com aplicação de $\mathrm{N}$ na semeadura absorveram mais $\mathrm{N}$ que as dos tratamentos sem aplicação de $\mathrm{N}$ na semeadura, nas duas épocas de semeadura após a dessecação, em Eldorado do Sul (tabela 2). Nos estádios de 10-11 folhas e de pendoamento, somente o tratamento sem aplicação de $\mathrm{N}$ foi inferior aos demais. Em Passo Fundo, apenas no estádio de 3-4 folhas, as plantas dos tratamentos com aplicação de $\mathrm{N}$ na semeadura absorveram mais $\mathrm{N}$ do que as sem aplicação de $\mathrm{N}$ na semeadura, nas duas épocas de semeadura.

Os resultados obtidos em sucessão à ervilhaca em Eldorado Do Sul diferiram da expectativa. Esperava-se não haver resposta à aplicação de $\mathrm{N}$ na semeadura do milho, devido à ervilhaca ser uma leguminosa e, portanto, possuir a capacidade de fixar o $\mathrm{N}_{2}$ atmosférico e à sua baixa relação $\mathrm{C} / \mathrm{N}$ liberar $\mathrm{N}$ mais rapidamente dos restos culturais (SÁ, 1995, PAVINATO et al., 1994). Porém, os dados evidenciaram que as quantidades de $\mathrm{N}$ liberadas pelos resíduos de ervilhaca não foram suficientes para suprir as necessidades iniciais do milho, havendo menor absorção de $\mathrm{N}$ (tabela 2). Provavelmente, esta deficiência ocorreu em função do baixo rendimento de massa seca de ervilhaca obtido em Eldorado do Sul (2,1t/ha) em relação a Passo Fundo (4,3t/ha) (tabela 4).

Em Eldorado do Sul, não se constatou efeito de época de semeadura de milho após a dessecação da ervilhaca na absorção de $\mathrm{N}$, em todos os estádios avaliados (tabela 2). Em Passo Fundo, somente no estádio de 3-4 folhas, o atraso na época de semeadura em 20 dias aumentou a absorção de $\mathrm{N}$ pelas plantas de milho em todos os sistemas de manejo de $\mathrm{N}$, embora, estatisticamente, não tenha havido diferença entre épocas no tratamento com aplicação de $60 \mathrm{~kg} / \mathrm{ha}$ de $\mathrm{N}$ na semeadura e de $100 \mathrm{~kg} / \mathrm{ha}$ de $\mathrm{N}$ em cobertura.

A resposta da absorção de $\mathrm{N}$ ao atraso na época de semeadura do milho, bem como à aplicação de $\mathrm{N}$ na semeadura em sucessão à ervilhaca pode ser atribuída, principalmente, à possível imobilização de $\mathrm{N}$ nos períodos iniciais da decomposição, até mesmo de resíduos de leguminosas com relação $\mathrm{C} / \mathrm{N}$ tão baixa quanto 15 , conforme verificado por JENSEN (1997).

Na comparação entre locais, constatou-se que nas duas épocas de semeadura, nos estádios de 3-4 folhas, 10-11 folhas e de pendoamento do milho, as plantas dos tratamentos sem aplicação de $\mathrm{N}$ na semeadura absorveram maiores quantidades de $\mathrm{N}$ em Passo Fundo em relação a Eldorado do Sul, exceto no estádio de 3-4 folhas na primeira época de semeadura, em que não houve diferença estatística entre locais (tabela 2). Nos tratamentos com aplicação de $\mathrm{N}$ na semeadura, apenas no estádio de 10-11 folhas, houve diferença, sendo superior em Passo Fundo. No estádio de 6-7 folhas, apenas o tratamento sem aplicação de $\mathrm{N}$ proporcionou menor absorção de $\mathrm{N}$ em Eldorado do Sul em relação a Passo Fundo. Nos tratamentos com aplicação de N, a absorção de $\mathrm{N}$ pelas plantas de milho foi superior em Eldorado do Sul.

Em sucessão à área de pousio invernal, em todos os estádios avaliados, as plantas de milho dos tratamentos com aplicação de $\mathrm{N}$ na semeadura absorveram maior quantidade de $\mathrm{N}$ do que as dos tratamentos sem aplicação de $\mathrm{N}$ na semeadura, nas duas épocas de semeadura, apesar de, estatisticamente, nos estádios de 10-11 folhas e de pendoamento não ter havido diferença na absorção de $\mathrm{N}$ entre as plantas dos tratamentos com aplicação de $\mathrm{N}$ na semeadura e as do tratamento com aplicação total de $\mathrm{N}$ em cobertura, em Eldorado do Sul (tabela 3). Em Passo Fundo, apenas no estádio de 3-4 folhas, a absorção de $\mathrm{N}$ foi superior nas plantas dos tratamentos com aplicação de $\mathrm{N}$ na semeadura em relação às dos tratamentos sem $\mathrm{N}$ na semeadura.

Quanto às épocas de semeadura após a dessecação, no tratamento de pousio invernal, verificou-se efeito apenas no estádio de pendoamento do milho em Passo Fundo, em que a absorção de $\mathrm{N}$ foi superior na segunda época em todos os sistemas de manejo de $\mathrm{N}$, com exceção do tratamento com aplicação de $30 \mathrm{~kg} / \mathrm{ha}$ de $\mathrm{N}$ na semeadura e de $130 \mathrm{~kg} / \mathrm{ha}$ de $\mathrm{N}$ em cobertura, em que a absorção de $\mathrm{N}$ foi superior na primeira época (tabela 3).

No estádio de 3-4 folhas, a absorção de N foi semelhante entre os locais, independentemente da época de semeadura após a dessecação e do sistema de manejo de N (tabela 3). No estádio de 6-7 folhas, em todos os sistemas de manejo de $\mathrm{N}$, houve maior absorção de $\mathrm{N}$ pelas plantas em Eldorado do Sul em relação a Passo Fundo, apesar de, estatisticamente, não haver diferença entre locais no tratamento sem N. No estádio de 10-11 folhas, 
independentemente do sistema de manejo de $\mathrm{N}$, constatou-se maior absorção de $\mathrm{N}$ em Passo Fundo. No pendoamento, na semeadura 1 dia após a dessecação, houve diferença entre locais apenas no tratamento com aplicação total de $\mathrm{N}$ em cobertura, sendo a absorção de N superior em Passo Fundo. Já, na semeadura aos 20 dias após a dessecação, em todos os sistemas de manejo de $\mathrm{N}$, a absorção de $\mathrm{N}$ foi maior em Passo Fundo em relação a Eldorado do Sul, com exceção do tratamento com aplicação de $30 \mathrm{~kg} / \mathrm{ha}$ de $\mathrm{N}$ na semeadura e de $130 \mathrm{~kg} / \mathrm{ha}$ de $\mathrm{N}$ em cobertura, em que a absorção de $\mathrm{N}$ foi similar entre locais.

\section{CONCLUSÕES}

A absorção de $\mathrm{N}$ pela planta de milho é influenciada pelo local, pela espécie de cobertura de solo no inverno, pela época de semeadura do milho após a dessecação das plantas de cobertura de solo e pelo sistema de manejo de N.

Somente em Eldorado do Sul, a aplicação de $\mathrm{N}$ na semeadura é benéfica pois aumenta a absorção de $\mathrm{N}$ pelo milho em relação ao tratamento com todo o $\mathrm{N}$ em cobertura.

$\mathrm{O}$ atraso na época de semeadura do milho em 20 dias após a dessecação é recomendado, principalmente quando em sucessão à aveia preta.

A absorção de N no milho em sucessão à aveia preta é menor em Eldorado do Sul em relação a Passo Fundo.

$\mathrm{O}$ aumento na dose de $\mathrm{N}$ na semeadura do milho de 30 para $60 \mathrm{~kg} / \mathrm{ha}$ de $\mathrm{N}$ não se constitui em estratégia eficiente para aumentar a absorção deste nutriente, independentemente da espécie de cobertura de solo no inverno.

\section{REFERÊNCIAS BIBLIOGRÁFICAS}

AITA, C. Dinâmica do nitrogênio no solo durante a decomposição de plantas de cobertura: efeito sobre a disponibilidade de nitrogênio para a cultura em sucessão. In: FRIES, M.R.; DALMOLIN, R.S.D. (Coord.) Atualização em recomendação de adubação e calagem: ênfase em plantio direto. Santa Maria : Pallotti, 1997. p. 76-111.

AITA, C., CERETTA, C.A., THOMAS, A.L. et al. Espécies de inverno como fonte de nitrogênio para o milho no sistema de cultivo mínimo e feijão em plantio direto. Revista Brasileira de Ciência do Solo, Campinas, v. 18, n. 1, p. 101-108, 1994

AULAKH, M.S., DORAN, J.W., WALTERS, D.T. et al. Crop residue type and placement effects on denitrification and mineralization. Soil Science Society of America Journal, Madison, v. 55, n. 4, p. 1020-1025, 1991.

BRASIL. Ministério da Agricultura. Departamento Nacional de Pesquisa Agropecuária. Divisão de Pesquisa Pedológica. Levantamento de reconhecimento dos solos do Estado do Rio Grande do Sul, Recife: PNPM, 1973. 431 p. (Boletim Técnico)
CANTARELLA, H. Calagem e adubação do milho. In: BÜLL, L.T.; CANTARELLA, H. Cultura do milho: fatores que afetam a produtividade. Piracicaba: POTAFOS, 1993, p. 147-198.

COMISSÃO DE FERTILIDADE DO SOLO - RS/SC. Recomendações de adubação e de calagem para os estados do Rio Grande do Sul e de Santa Catarina. Passo Fundo: SBCS-Núcleo Regional Sul, 1995. 224 p.

DA ROS, A.O., AITA, C. Efeito de espécies de inverno na cobertura do solo e fornecimento de nitrogênio ao milho em plantio direto. Revista Brasileira de Ciência do Solo, Campinas, v. 20, n. 1, p. 135-140, 1996.

DERPSCH, R., ROTH, C.H., SIDIRAS, N. et al. Controle da erosão no Paraná, Brasil: sistemas de cobertura do solo, plantio direto e preparo conservacionista do solo. Eschborn:GTZ/IAPAR, 1991. Importância da rotação de culturas: p. 147-164.

DOUGLAS, C.L., ALLMARAS, R.R., RASMUSSEN, P.E. $\boldsymbol{e}$ t al. Wheat straw composition and placement effects on decomposition in dryland agriculture of the Pacific Northwest. Soil Science Society American Journal, Madison, v. 44, n. 4, p. $833-837,1980$.

FORNASIERI FILHO, D. A cultura do milho. Jaboticabal: FUNEB, 1992. 273 p.

HEINZMANN, F.X. Resíduos culturais de inverno e assimilação de nitrogênio por culturas de verão. Pesquisa Agropecuária Brasileira, Brasília, v. 20, n. 9, p. 1021-1030, 1985.

IBGE. Levantamento de recursos naturais. Rio de Janeiro: IBGE, 1986. v. 33.796 p.

IPAGRO. Observações meteorológicas no Estado do Rio Grande do Sul. Porto Alegre: IPAGRO, 1979.180 p.

JANSEN, H.H., KUCEY, R.M.N. C, N, and S mineralization of crop residues as influenced by crop species and nutrient regime. Plant and Soil, Dordrecht, v. 106, n. 1, p. 35-41, 1988.

JENSEN, E.S. Nitrogen immobilization and mineralization during initial decomposition of $15 \mathrm{~N}$-labelled pea and barley residues. Biology Fertility Soils, Berlim, v. 23, p. 26-32, 1997.

KIHEL, E.J. Fertilizantes orgânicos. Piracicaba: Agronômica Ceres, $1985.210 \mathrm{p}$.

MOODY, J.E., SHEAR, G.M., JONES Jr., J.N. Growing corn without tillage. Soil Science Society of America Journal, Madison, v. 6, n. 5, p. 516-517, 1961.

MORENO, J.A. Clima do Rio Grande do Sul. Porto Alegre: Secretaria da Agricultura, 1961. 41 p.

MUZILLI, O., OLIVEIRA, E.L. O milho no Paraná. Londrina: Fundação Instituto Agronômico do Paraná, 1992. Nutrição e adubação: p. 88-95. (Circular, 29).

PAVINATO, A., AITA, C., CERETTA, C.A. et al. Resíduos culturais de espécies de inverno e o rendimento de grãos de milho no sistema cultivo mínimo. Pesquisa Agropecuária Brasileira, Brasília, v. 29, n. 9, p. 427-432, 1994. 
REINERTSEN, S.A., ELLIOT, L.F., COCHRAN, V.L., et al. Role of available carbon and nitrogen in determining the rate of wheat straw decomposition. Soil Biology Biochemistry, Oxford, v. 16, n. 5, p. 459-464, 1984

RIBOLDI, J. Delineamentos Experimentais de Campo, Parte 1. Porto Alegre:Instituto de Matemática da UFRGS, 1993. 78 p. (Cadernos de matemática e estatística).

SÁ, J.C.M. de. Aspectos fisiológicos e adubação nitrogenada. Revista Plantio Direto, Passo Fundo, n. 3, p. 18-22, 1995.

SÁ, J.C.M. de. Manejo de fertilidade do solo no sistema plantio direto. In: EMBRAPA-CNPT, FUNDACEP, FECOTRIGO et al. (coord.). Plantio direto no Brasil. Passo Fundo: Aldeia Norte, 1993. p. 41-47.

SCHOMBERG, H.H., STEINER, J.L., UNGER, P.W. Decomposition and nitrogen dynamics of crop residues quality and water effects. Soil Science Society of America Journal, Madison, v. 58, n. 2, p. 372-381, 1994.

STOTT, D.E., ELLIOTT, L.F., PAPENDICK, R.I. et al. Low temperature or low water effects on microbial decomposition of wheat residue. Soil Science Society American Journal, Madison, v. 18, n. 3, p. 577-582, 1986.

TEDESCO, M.J., VOLKSWEISS, S.J., BOHEN, H. Análise de solo, plantas e outros materiais, Porto Alegre: Departamento de Solos da UFRGS, 1985. 188 p. (Boletim Técnico, 5).

TEIXEIRA, L.A.J., TESTA, V.M., MIELNICZUK, J. Nitrogênio do solo, nutrição e rendimento de milho afetados por sistemas de cultura. Revista Brasileira de Ciência do Solo, Campinas, v. 18 , n. 2 , p. $207-214,1994$.

TIAN, G., KANG, B.T., BRUSSAARD, L. Mulching effect of plant residues with chemically contrasting compositions on maize growth and nutrient accumulation. Plant and Soil, Netherlands, v. 153, n. 2, p. 179-187, 1993.

TOLLENAAR, M., MIHAJLOVIC, M., VYN, T.J. Corn growth following cover crops: influence of cereal cultivar, cereal removal, and nitrogen rate. Agronomy Journal, Madison, v. 85 , n. 2 , p. $251-255,1993$.

VICTORIA, R.L., PICCOLO, M.C., VARGAS, A.A.T. O ciclo do nitrogênio. In: CARDOSO, E.J.B.N., TSAI, S.M., NEVES, M.C.P. (Coord.) Microbiologia do Solo. Campinas: Sociedade Brasileira de Ciência do Solo, 1992. p. 105-120.

Ciência Rural, v. 29, n. 4, 1999. 